\title{
AN OVERVIEW OF EUROPEAN EFFORTS IN GENERATING CLIMATE DATA RECORDS
}

\author{
Z. Su, W. Timmermans, Y. Zeng, J. Schulz, V. O. John, R. A. Roebeling, P. Poli, D. Tan, \\ F. Kaspar, A. K. Kaiser-Weiss, E. Swinnen, C. Toté, H. Gregow, T. Manninen, A. Rilihelä, \\ J.-C. Calvet, Y. Ma, and J. Wen
}

The CORE-CLIMAX project has delivered methods and assessments of the capability to provide climate data records, processes for deriving and validating these records, and opportunities to feed back the lessons learned from reanalysis.

T he Coordinating Earth Observation Data Validation for Reanalysis for Climate Services project (CORECLIMAX; see the appendix for a list of the key acronyms used in this paper) was conducted in support of the establishment of the C3S and other international activities, such as the formulation of the architecture for climate monitoring from space conducted by major space agencies.

AfFiliationS: Su, Timmermans, AND ZenG-Faculty of GeoInformation and Earth Observation (ITC), University of Twente, Enschede, Netherlands; SCHULZ, JOHN, AND RoEbeLING-European Organisation for the Exploitation of Meteorological Satellites, Darmstadt, Germany; PoLI-Centre de Météorologie Marine, Météo-France, Brest, France; TAN-European Centre for MediumRange Weather Forecasts, Reading, United Kingdom; KASPAR AND KAISER-WeISS-National Climate Monitoring, Deutscher Wetterdienst, Offenbach, Germany; SWINNEN AND TOTÉ-Remote Sensing Unit, Flemish Institute for Technological Research (VITO), Mol, Belgium; Gregow, MANNINeN, AND RIIHELÄ-Finnish Meteorological Institute, Helsinki, Finland; CALVET-Météo-France, CNRM, Toulouse, France; MA-Key Laboratory of Tibetan Environment Changes and Land Surface Processes, Institute of Tibetan Plateau Research, Chinese Academy of Sciences, and CAS Center for
A major objective of CORE-CLIMAX was to systematically assess the capacity of ongoing European activities in the area of generation and provision of CDRs. With respect to C3S, the roles of in situ data and model-based reanalysis data need to be considered as well. As the in situ datasets are generally under national responsibility, the CORE-CLIMAX assessment did not cover all in situ data records generated

Excellence in Tibetan Plateau Earth Sciences, Chinese Academy of Sciences, and University of Chinese Academy of Sciences, Beijing, China; WeN-Plateau Atmosphere and Environment Key Laboratory of Sichuan Province, College of Atmospheric Sciences, Chengdu University of Information Technology, Chengdu, China CORRESPONDING AUTHOR: Z. Su, z.su@utwente.nl

The abstract for this article can be found in this issue, following the table of contents.

DOI:10.1175/BAMS-D-16-0074.I

A supplement to this article is available online (10.II75/BAMS-D-I6-0074.2)

In final form 28 August 2017

(C)2018 American Meteorological Society

For information regarding reuse of this content and general copyright

information, consult the AMS Copyright Policy. 
by European providers. However, the inclusion of some of the best-known in situ data records in the assessment has demonstrated the value of the tools developed in CORE-CLIMAX and encourages more nationally managed data records to be included in a future assessment.

Another objective of CORE-CLIMAX was to coordinate the identification of available physical measurements, which can be reconciled with previously existing data records, to form long time series. With the GCOS, Copernicus, and ESA CCI projects, along with EUMETSAT and its SAF network, coordination took place with specific efforts to be undertaken by new Copernicus projects to further upgrade their product catalogs to include climate-relevant validation and information and lay the observational basis for service activities. CORE-CLIMAX identified the integration of CDRs into the reanalysis chain by proposing a feedback mechanism ensuring that the results of the reanalysis process get appropriately reflected into updates of the CDRs and proposed and evaluated methods for intercomparing different reanalyses.

The present paper is structured to report on the four main achievements of the project: 1) synthesize European activities in generating ECVs by proposing a structured process for quality-controlled elaboration of CDRs, 2) propose a generic validation process for qualifying the accuracy of ECVs, 3) propose a feedback mechanism ensuring that the results of the reanalysis process get appropriately reflected into updates of the CDR, and 4) propose a process for comparing reanalyses.

\section{ASSESSMENT OF EUROPEAN CAPABIL- ITY TO PROVIDE ECV CLIMATE DATA RECORDS. Developing ECV CDRs poses many} challenges because of the varied use of climate data, the complexities of data record generation, and the difficulties in sustaining the activities over extended periods of time. A quality-controlled process is needed to generate, evaluate, and maintain CDRs, as well as to communicate information to the scientific and climate service user communities in an understandable way by providing guidance. For the climate service community, it is essential to know which CDRs exist, their level of quality, the degree of completeness and sustainability, and what is planned for the future.

One major objective of the CORE-CLIMAX project was to systematically assess the capacity of ongoing European activities in the area of generation and provision of CDRs to support the establishment of the C3S. CORE-CLIMAX provided means that support the selection of CDRs for the C3S based on their scientific, technical, and usage status. On the basis of the maturity matrix method pioneered by Bates and Privette (2012) for satellite data, CORE-CLIMAX extended that approach to all CDRs, encompassing in situ, combined satellite and in situ, and reanalysis data (Schulz et al. 2017, manuscript submitted to Geosci. Data J., hereafter SGDJ).

Consultation about the adapted approach with many leading initiatives in Europe, such as EUMETSAT's SAF network and the ESA CCI projects, and internationally with the WMO, CEOS WGC, NOAA, and USGS, led to the awareness that three different aspects in general needed to be considered. First are the scientific, engineering, and information preservation practices; second, the usage of products including feedback and update mechanisms; and last but not least, the quality of products with respect to applications. This led to the definition of three major elements for the capacity assessment:

- Unified data record descriptions were created that contain technical specifications as well as information on quality.

- An SMM (SGDJ) that evaluates if the production of a data record follows best practices for specific scientific, engineering, and information preservation aspects, as well as for facilitation of usage was developed. The SMM is principally designed to be used without considering specific applications and therefore does not depend on evolving user and application requirements. The data records are evaluated in six main categories: i) software readiness; ii) metadata; iii) user documentation; iv) uncertainty characterization; v) public access, feedback, and update; and vi) usage. Each of the main categories is divided into several subcategories, which are each rated on the basis of six maturity levels. An example of the SMM is shown in Fig. 1.

- An APM (SGDJ) is developed that attempts to evaluate the performance of an ECV CDR with respect to the user requirements of a specific application, utilizing information provided by the technical specifications of a data record, as well as by the public sources, such as data record quality assessments performed during GEWEX (e.g., Stubenrauch et al. 2013). The most important technical specifications evaluated include quantitative information on i) coverage, ii) sampling, iii) uncertainty, and iv) stability.

Assessment exercise and results. The SMM and APM were tested during a capacity assessment workshop 


\begin{tabular}{|c|c|c|c|c|c|}
\hline $\begin{array}{l}\text { Software } \\
\text { Readiness }\end{array}$ & Metadata & $\begin{array}{c}\text { User } \\
\text { Documentation }\end{array}$ & $\begin{array}{c}\text { Uncertainty } \\
\text { Characterisation }\end{array}$ & $\begin{array}{l}\text { Public access, } \\
\text { feedback, } \\
\text { and update }\end{array}$ & Usage \\
\hline Coding Standards & Standards & $\begin{array}{c}\text { Formal description of } \\
\text { scientific } \\
\text { methodology } \\
\end{array}$ & Standards & $\begin{array}{c}\text { Public } \\
\text { Access/Archive } \\
\end{array}$ & Research \\
\hline $\begin{array}{c}\text { Software } \\
\text { Documentation }\end{array}$ & $\begin{array}{c}\text { Collection } \\
\text { level }\end{array}$ & $\begin{array}{c}\text { Formal validation } \\
\text { report }\end{array}$ & Validation & Version & $\begin{array}{l}\text { Decision } \\
\text { support } \\
\text { system }\end{array}$ \\
\hline $\begin{array}{c}\text { Numerical } \\
\text { Reproducibility } \\
\text { and portability } \\
\end{array}$ & File level & $\begin{array}{l}\text { Formal product user } \\
\text { guide }\end{array}$ & $\begin{array}{l}\text { Uncertainty } \\
\text { quantification }\end{array}$ & $\begin{array}{l}\text { User feedback } \\
\text { mechanism }\end{array}$ & \\
\hline Security & & $\begin{array}{c}\text { Formal description of } \\
\text { operations concept }\end{array}$ & $\begin{array}{l}\text { Automated quality } \\
\text { monitoring }\end{array}$ & Updates to record & \\
\hline \multicolumn{6}{|c|}{ Legend } \\
\hline 1 & 2 & 3 & 4 & 5 & 6 \\
\hline
\end{tabular}

FIG. I. Example of a CORE-CLIMAX SMM. The colors mark the maturity scores achieved. Maturity scores I and 2 denote research capability (i.e., many aspects of the CDR are still under development). Maturity scores 3 and 4 mark initial operations capability, which means the CDR is available to the user community, its usefulness is demonstrated, and decisions need to be made to sustain its maintenance and further development. Maturity scores 5 and 6 indicate full operations capability, where the production of the CDR is in a mature operational environment.

on 21-23 January 2014 at EUMETSAT headquarters in Darmstadt, Germany, where some 40 participants represented a diverse set of European CDR producers and stakeholders.

This allowed for an overview of the European capacity to generate CDRs and offered the CDR producers the opportunity to conduct self-assessments of the maturity of their CDRs. These CDRs included satellite and in situ data records as well as reanalysis output. Among the satellite data providers were EUMETSAT and its SAF network, the ESA CCI, and Copernicus Atmosphere and Land Services. Major European players responsible for in situ data records who actively participated in the assessment including the Met Office Hadley Centre (responsible for several HadObs datasets), Deutscher Wetterdienst (responsible for the GPCC), KNMI (which is leading the ECA\&D project), and the Alfred Wegener Institute, which is responsible for the BSRN archive. One global reanalysis producer, the ECMWF, which generates the ERA-Interim dataset, also took part.

The main assessment results demonstrated a high variance in the FCDR scores. Also, the more operational a service is, the higher the scores are for software readiness, metadata, user documentation, and public access. It was further noted that operational TCDRs achieved generally high scores for metadata, user documentation, public access, and usage, whereas sometimes medium scores were seen for software readiness and uncertainty characterization. On the other hand, for scientific TCDRs high scores for user documentation, uncertainty characterization, and usage were seen, whereas lower scores were seen for software readiness and public access. From these differences and prior history of the products, it can be deduced that getting consistently high scores in all categories takes approximately $5-10 \mathrm{yr}$. This generally requires, however, a transfer of data record production from scientific to operational environments, while keeping the scientific expertise on board.

The assessment of in situ datasets appeared sometimes to be difficult because the data records are often continually updated, with no concept of versioning, or with a version that differed from the satellite datasets. Furthermore, the maturity of the in situ data largely depends on the selection of the set of stations or the time period.

As the SMM is based on "best practices," reviews and changes to the SMM are only expected on rather long time scales $(\sim 10 \mathrm{yr})$. However, it is proposed to review and eventually change the SMM of a CDR prior to its release (e.g., by the $\mathrm{C} 3 \mathrm{~S}$ with its EQC function). The full details of the assessment results of the 37 CDRs are given by John et al. (2015).

\section{Structured process to generate climate data records. The} assessment of the capacity to generate CDRs is only a small part of a bigger structured process that can be derived by a decomposition of the "climate record creation and preservation" pillar in the logical view of the architecture for climate monitoring from space (Dowell et al. 2013). As such, the process of generating CDRs refers to categories and subcategories in the SMM, and subdiagrams must be defined within this pillar. Individual diagrams are also needed for the documentation, archiving, access, and user feedback 


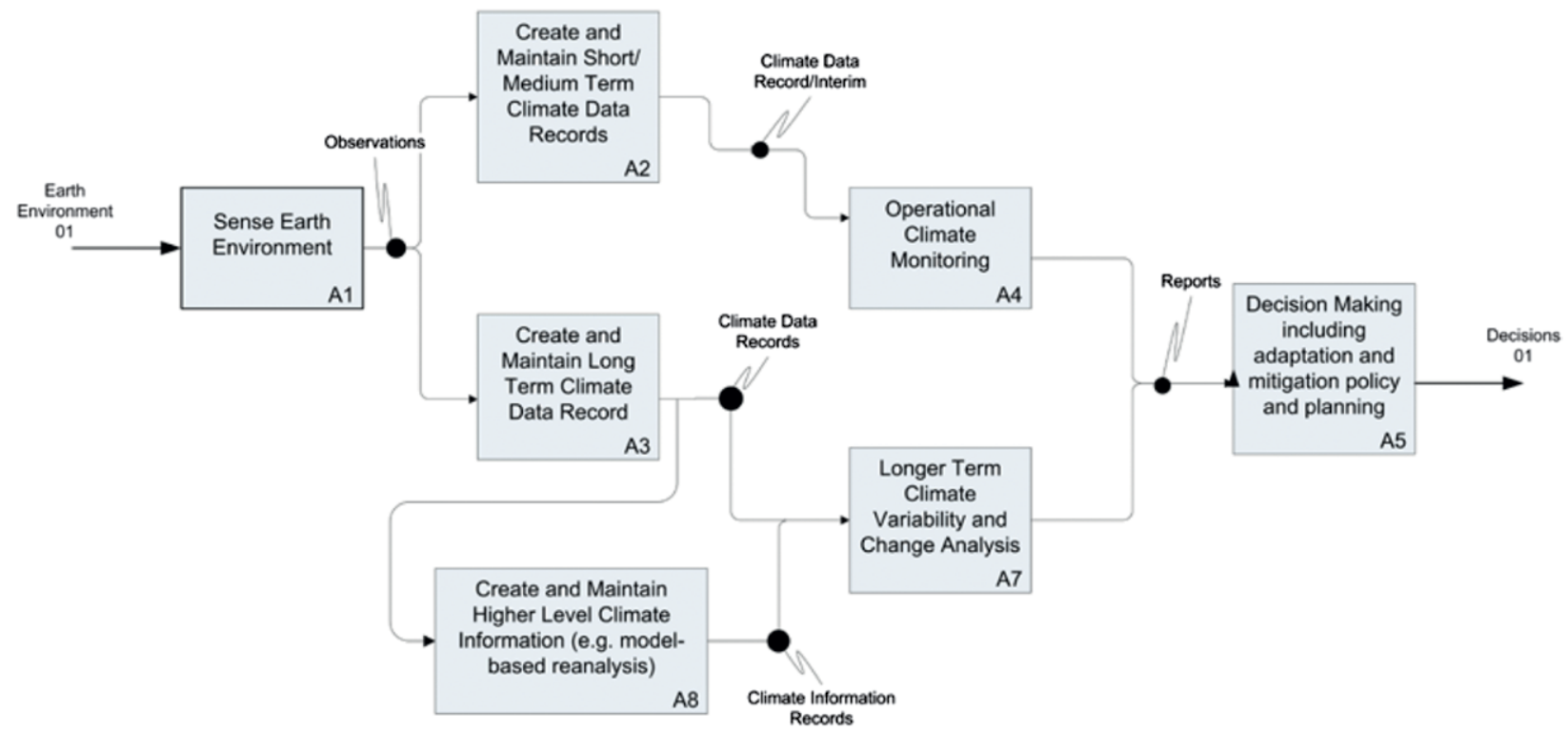

Fig. 2. Decomposition of the logical view of the architecture for climate monitoring from space (Dowell et al. 2013).

aspects. The details of this structured process for deriving CDRs are given in Schulz (2015).

Figure 2 shows the decomposition at the first level. Boxes A2, A3, and A8 represent the three different activities that create data records for different applications. Box A3 shows the classical approach to creating long-term CDRs, which are mostly used to study decadal variability and trends (box A7).

The structure of this logical view has the major advantage that for each of the boxes, responsible organizations can be identified. For instance, the creation and maintenance of CDRs (functions A2 and A3) involve many activities including the creation of FCDRs that are best performed by space agencies operating the specific satellite sensor. In contrast, the generation of higher-level climate information records, such as climate indices, or the number of storms that make landfall in a certain region, often need the combination of both CDRs originating from spaceborne and ground-based systems, as well as modeling components (e.g., through some form of reanalysis). Thus, such activity might be best placed in an organization that combines several sources of information. This includes reanalysis centers, but also climate service centers, and meteorological and environmental agencies.

The actual creation and maintenance of CDRs (function A3) can be further decomposed (as shown in Fig. 3) into the following components: sensor corrections and geolocation, calibration and intercalibration, conversion to a geophysical parameter, validation versus requirements, archive and access to data, and a user feedback mechanism (together with the documentation and review processes). This view contains many subcategories of the maturity matrix that describe the best practice for the indicated activities. Detailed descriptions of these lower-level processes can be found in Schulz (2015).

\section{A HARMONIZED APPROACH FOR CDR VALIDATION. The generation of ECVs needs} to put strong emphasis on the generation of fully described error-characterized and consistent data products. For example, generation of many ECVs requires ancillary information about the state of the atmosphere (e.g., cloud screening for SST, atmospheric correction for spaceborne sensors). As such, the consistency between the various ECV products (e.g., cloud or sea ice masks) extends to ensuring consistency in the approaches of CDR generation. The validation process, as an integral component of the CDR processing chain, is critical to ensuring such consistency.

A need for a generic validation strategy. The WGCV defines validation as the process of assessing, by independent means, the quality of the data products derived from satellite observations. This so-called product validation ensures that the quality of the products is properly assessed, through quantification of the uncertainties in both the data itself and the measurement system deployed for generating the data. Hence, validation can be considered an end-to-end process that encompasses the entire system, from sensor to product.

As the purpose of calibration and validation is to provide confidence in the quality of the FCDRs/TCDRs 


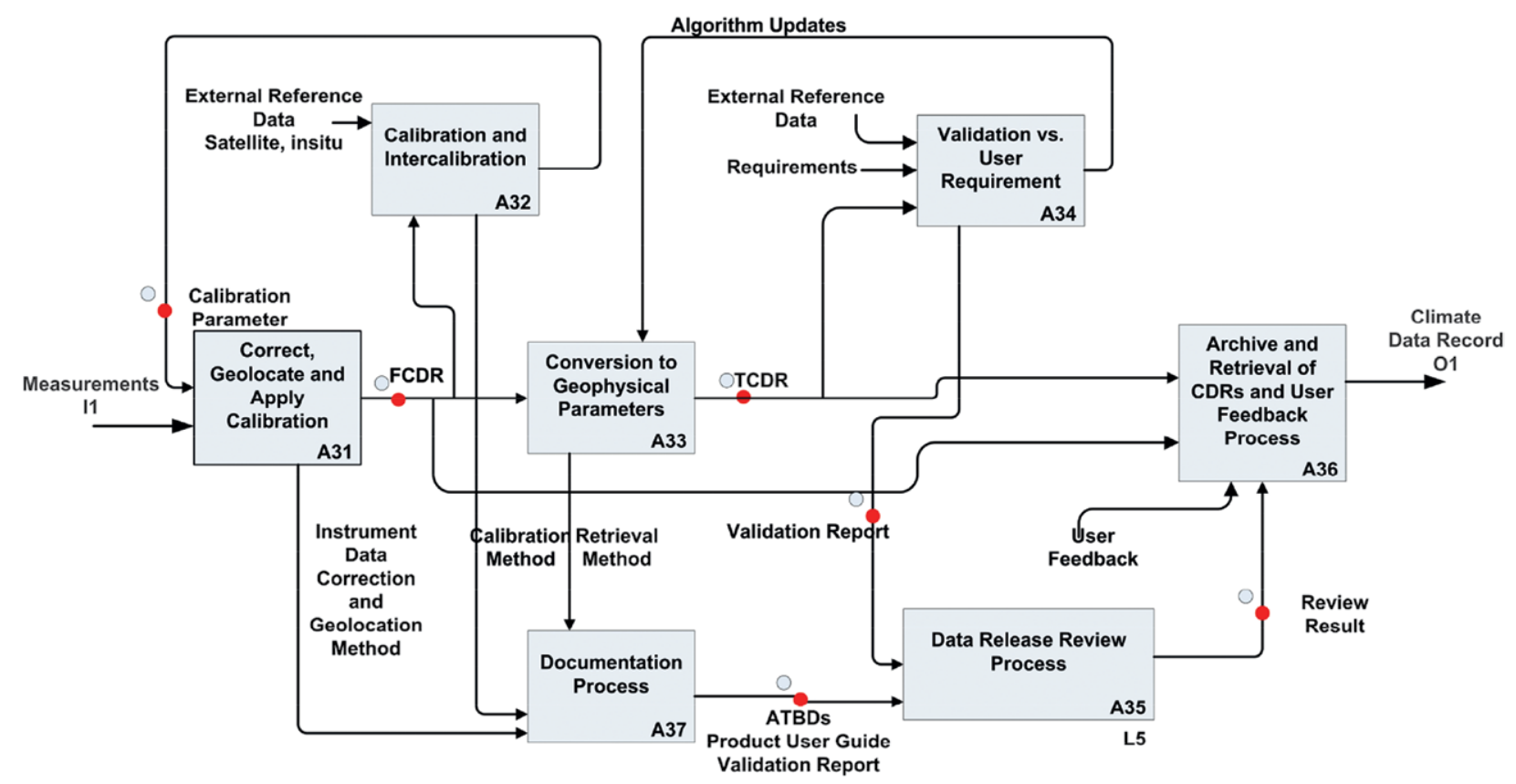

FIG. 3. Decomposition of the create and maintain long-term CDRs (box A3) from Fig. 2.

and their uncertainties, information is required on how the calibration and validation activities are carried out, at each stage of the data process chain. To establish the traceability of a validation process, one first needs to document each step of the validation process. After an analysis of current validation practices in Europe for space-based ECV CDRs, a generic validation strategy was developed in CORE-CLIMAX (Zeng et al. 2014a).

Starting with documenting the generation of socalled reference datasets, the generic process then requires the assessment of the independence level of the product with respect to such datasets (see Fig. 4). Using the quality-controlled reference datasets, the data producer can make a self-assessment. A complete validation process should also consider the internal consistency of the validated CDRs (e.g., comparing the physically interrelated variables). Ideally, independent assessments should be carried out, subject to external review. Finally, qualification of the independence levels of the independent assessment and the external review are required. The last step consists of allowing future repeats, by sustaining the established validation facilities and procedures. This repeat step implies achieving an operational level of service, so that validation activities and data releases are regularly/routinely implemented.

Importance of consistency validation. The CDS of C3S plans to include ECV CDRs and associated uncertainty estimates. These may originate from reanalyses, models (of various types, such as seasonal forecasts and up-to-date climate projections), and in situ or satellite data. Furthermore, the CDS should contain only "climate compliant" data, as defined by the EQC function of C3S. This implies that one may find a certain ECV from different sources, and there is a user need to determine which dataset is most suited for a particular purpose. On the other hand, when there is a certain ECV variable under evaluation, one would like to collect as many independent datasets as possible, assuming they represent the same variable, to carry out (inter)comparison, and try to apprehend associated uncertainties. This requires thorough (inter) comparisons, from two angles: i) (inter)comparisons among multiple independent datasets/products, for a specific (the same) physical variable, and ii) (inter) comparisons among multiple (different) physical variables that are related to each other.

The first type of (inter)comparisons can be implemented at point or grid scales, to look for product differences and their reasons (Zeng et al. 2015, 2016), whereas the second type of (inter)comparisons checks the physical consistency from a functional point of view. Note that coupled data assimilation systems (e.g., ocean and atmosphere) offer a third way to check for the physical consistency of ECVs across domains (i.e., the third type).

These three types of validation activities together can be regarded as a quality consistency check on climate data products. To this end, the validation data (inputs, outputs, and ancillary data), tools, and documentation should be archived together and made 


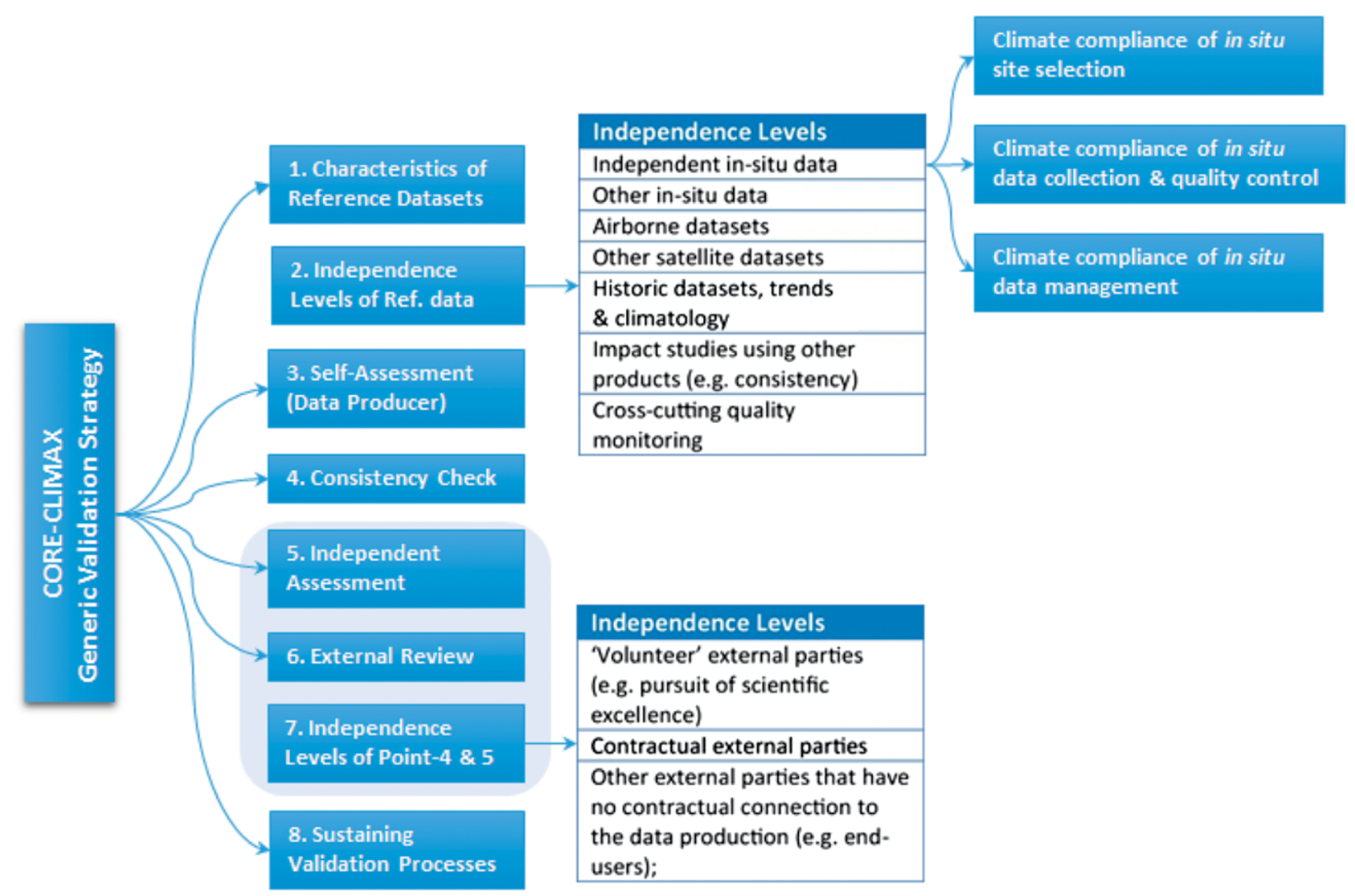

FIG. 4. CORE-CLIMAX generic validation strategy for space-based climate data records of ECV. The eight steps help to provide detailed information on how the validation activities are carried out, and to establish the traceability of a validation process.

publicly accessible to facilitate openness, repeatability, transparency, and scrutiny. An example of applying this generic validation strategy in the Yangtze River basin (Huang et al. 2015; Zeng et al. 2014b) is given in the sidebar.

REANALYSIS FEEDBACK MECHANISM TO CDR UPDATES. Procedure for feeding back improved ancillary data to assist CDR updates. The generation of ECV in the form of CDRs from observing system's "raw data" uses ancillary data as a representation of environmental components that cannot be estimated from the observed data alone. Such ancillary data often come from reanalysis datasets. After first reviewing the procedures currently in place for providing CDR generation with ancillary data from reanalysis products, the limitations of the current approaches were identified (Poli et al. 2013). Several measures were further proposed to enhance this generation process, in particular by using consistent data from reanalysis products.

Support infrastructure for CDR quality assessment in a reanalysis environment. Use of the reanalysis environment for quality assessment of observational CDRs is set to grow significantly in the coming decades, as more CDRs are becoming available from Earth observation programs gathering present-day observations, and also from efforts to generate historical CDRs. The reanalysis environment provides many opportunities for assessing the quality of observational CDRs, for example, by analyzing a posteriori the information produced by the data assimilation procedure that plays a key role in the reanalysis process.

However, a reanalysis-based assessment of observational CDRs depends on having a substantial support infrastructure. The main elements that are accessible to CDR providers, to assist them in making appropriate preparations for receiving maximum benefit from the reanalysis feedback, have been outlined by Tan and Poli (2013). Full benefit is only possible when the observational CDRs are supplemented with appropriate documentation, metadata, and auxiliary tools.

The infrastructure is framed toward iterative assessments, designed to improve CDRs via provision of quantitative feedback at the datum level as well as analytical feedback in the form of assessment reports. A distinction is made between offline assessments 
(projecting an existing reanalysis into the CDR physical space) and online assessments (ingesting the CDR in the assimilation component of the reanalysis system). Satisfactory offline assessments are typically a prerequisite, together with additional data assimilation developments, for online assessments.

Identifying these infrastructure needs was facilitated by two sources of information: the CORE-CLIMAX visiting program, and the CMUG of the ESA CCI, both of which enabled direct contact with a diverse range of CDR providers, from both the in situ and the satellite-based communities. Some of the overarching considerations are as follows: i) Quantitative feedback at the observation datum level is desired; this can be addressed by projecting reanalysis into the CDR space in both offline and online assessments. ii) Meaningful comparison and statistical analysis requires appropriate clustering of similar observations, segregation of dissimilar observations, and good characterization of fluctuations in quality (especially a lack of temporal consistency); this can be addressed by access to appropriate metadata. iii) Feedback should be provided incrementally and the quantitative feedback should be extensible; this can be addressed by multiple feedback loops and a database approach. iv) There is value in making the quantitative feedback available to third parties; this can be addressed by incorporating a "third-party feedback loop."

Procedures for feeding back reanalysis results and plans to CDR producers. Recommendations were made by Tan et al. (2014) on how reanalysis needs can be systematically communicated to CDR producers and effectively actioned within CDR update plans. The principal conclusion is that effective communication of reanalysis needs should involve procedures at two levels: i) the peer-to-peer level, which allows communication of feedback from reanalysis results, particularly the results of CDR quality assessment arising from the reanalysis environment, and ii) the synthesis level, which promotes coordination and improves the efficiency of peer-to-peer level communications. For the latter, two types of synthesis situations may arise: i) coordination of efforts between multiple CDR producers and ii) consolidation of feedback from multiple users for formulating a CDR update plan.

By building the underlying technical solutions (e.g., design and implementation of suitable databases and tools), progress will be reflected by increased maturity ratings of the CORE-CLIMAX SMMs. The current international context contains a number of programs and initiatives with mechanisms for conducting CDR assessments and compiling user needs (Gregow et al. 2014a, 2016), but further work is required to establish consolidated best practices and improve coordination within and between such activities. Further consideration of programmatic issues is discussed by Schulz (2015).

A process to intercompare reanalysis. Reanalysis intercomparison activities are a key component of characterizing reanalysis uncertainties. As such, they yield information that assists users in deciding which reanalysis product might be most suitable for their particular application. The CORE-CLIMAX project developed a set of procedures for comparing reanalyses and for comparing reanalyses to assimilated observations and CDRs (Gregow et al. 2014b; Kaiser-Weiss et al. 2015). To do so, five categories of comparisons were identified: i) descriptive product comparison, ii) comparison with third-party observation-based CDRs, iii) intercomparison between different reanalyses, iv) thematic comparison (i.e., how well can the reanalysis products be applied to understand a particular problem), and v) internal metrics comparison.

\section{CONCLUSIONS AND RECOMMENDA-} TIONS. The CORE-CLIMAX project aimed to substantiate how Copernicus observations and products (from both in situ and space components) can contribute to climate change analyses. CORECLIMAX assessed the European capability to provide ECV CDRs, prepared a structured process to derive CDRs, coordinated a harmonized approach for validating ECV CDRs, identified the integration of CDRs into the reanalysis chain, and formulated a process to compare the results of different reanalysis techniques. With respect to the development of C3S, by means of a worldwide survey and intercomparison between global reanalysis and regional reanalysis, recommendations were reported in Gregow et al. (2016) on the climate data store, sectoral information system, evaluation and quality control, outreach and dissemination, as well as coordination. Detailed descriptions of all above aspects can be found online (www.coreclimax.eu/) and in the online supplemental material (https://doi.org/I0.II75/BAMS -D-16-0074.2). In addition to the intercomparison of diverse products from the same ECV, which has added value on its own, we would like to emphasize that there is also added value in several products with quantified uncertainties for a range of applications.

CORE-CLIMAX can be compared to setting up ISO procedures when it comes to quality standards concerning CDR/ECV/reanalysis products (i.e., time 
TWS is achieved by balancing precipitation, evaporation, and river runoff from satellite observations and in situ observations. The same is also obtained from ERA-Interim data (Dee et al. 20II). Upon comparing these TWS data to the GRACE observations of storage changes (Landerer and Swenson 2012), we can spot the potential quality issues between different versions of GRACE observations.

Data. The TWS anomaly and cumulative TWS anomaly are estimated from GPCP precipitation (Adler et al. 2003), surface energy balance system (SEBS)estimated evapotranspiration (Chen et al. 2014), observed discharge, as well as from ERA-Interim data (Dee et al. 20II), which are compared with GRACE TWS (Landerer and Swenson 20I2) for the upper Yangtze River reach and the whole Yangtze River basin. The river discharge measurements from Yichang station for the period 200I-10 are used for the upper reach study. The discharge measurements from Datong for the period 2005-10 are used for the whole Yangtze River basin study. The GPCP precipitation data were obtained online (http://jisao.washington.edu/data

/gpcp/), as were the GRACE data (http:// grace.jpl.nasa.gov/, data version RL05 .DSTVSCSI40I). The GRACE monthly gridded data represent an equivalent water thickness deviation to the average from January 2004 to December 2009.

Results. From the results shown in Figs. SBIa,b, it can be seen that the TWS results derived from the observation data and from ERA-Interim data are consistent with each other, indicating both datasets capture the surface dynamics of the water cycle fluxes. However, the TWS derived from GRACE has somewhat larger amplitudes than those from the observations and the reanalysis data, indicating deep groundwater contributions. From Fig. SBIb, it may be concluded that after the filling of the Three Gorges Dam reservoir (Yichang station, top panel) started in 2004, the storage of the upper reach increased in the following years during the 2005-07 period, but returned to the average gradually afterward. This indicates the dominant climatic control of the Yangtze River system in the upper reach. For the lower reach, it can be seen that there was reduced storage from 2004 to 2008 but it gradually returned to its preThree Gorges Dam stage afterward.

It is noted that the monthly TWS anomaly and cumulative anomaly over Yichang station (i.e., the upper reach), calculated using an earlier version of the GRACE dataset (RL04 ssv201008), are different from the results shown in Figs. SBIa,b. For the TWS anomaly, the earlier version of the GRACE dataset has a phase difference of about 10 days, when compared to the current version. For the cumulative TWS anomaly, the earlier version did not show the increase in the monthly accumulative TWS anomaly after 2004, which was expected because of the filling of the Three Gorges Dam reservoir (Fig. SBIb, top).

Conclusions. The exact explanation for the different results over the upper Yangtze River reach, calculated from the two versions, needs intensive dedicated research.
However, the log file for each change made for the production of GRACE data can be accessed easily online (ftp://podaac .jpl.nasa.gov/allData/grace/docs/); therefore, the first action should be to check if the difference can be attributed to what has been changed during the production of the new version dataset.Another place to look at such information is the Center for Space Research website (www2.csr .utexas.edu/grace/RL05.html).

From the above two sources, the text quoted below may explain the possible reasons for the different results over the upper Yangtze River reach, with the two versions of data:

NOTE-I (2012-07-17): We have replaced the CSR-GSM products for the following four months: July-2004; October-2004; March-2005 and February-2006. The GSM products for these four months have been updated with the refined data editing. While the GAC/GAD products for these four months are unchanged, they have been updated as well, for consistency. If you downloaded the data products for these four months prior to July 17,2012 , please download the replacement products. No other products previously delivered are so affected.

As reported in the log file, the affected products for the four specific months correspond to the difference in the calculated monthly accumulative TWS anomaly after 2004 between the two versions of the GRACE dataset. series). As such, the project constitutes an important building block for developing climate services.

With respect to $\mathrm{C} 3 \mathrm{~S}$, the systematic application and further development of the CORE-CLIMAX SMM and the APM were strongly endorsed by participants of a C3S workshop on the content of the climate data store held in Reading, United Kingdom, during July 2015. We highly suggest building on the knowledge documented by the CORE-CLIMAX consortium in future implementations of climate services. So far the APM has not been widely tested by the user communities; efforts are needed in the future to generate awareness in user communities and for improvement.

More training is required in order to capitalize on what has been achieved in the CORE-CLIMAX project and more generally for the success of C3S, which hints both at improving university education as well as other education activities (e.g., ESA training activities). 

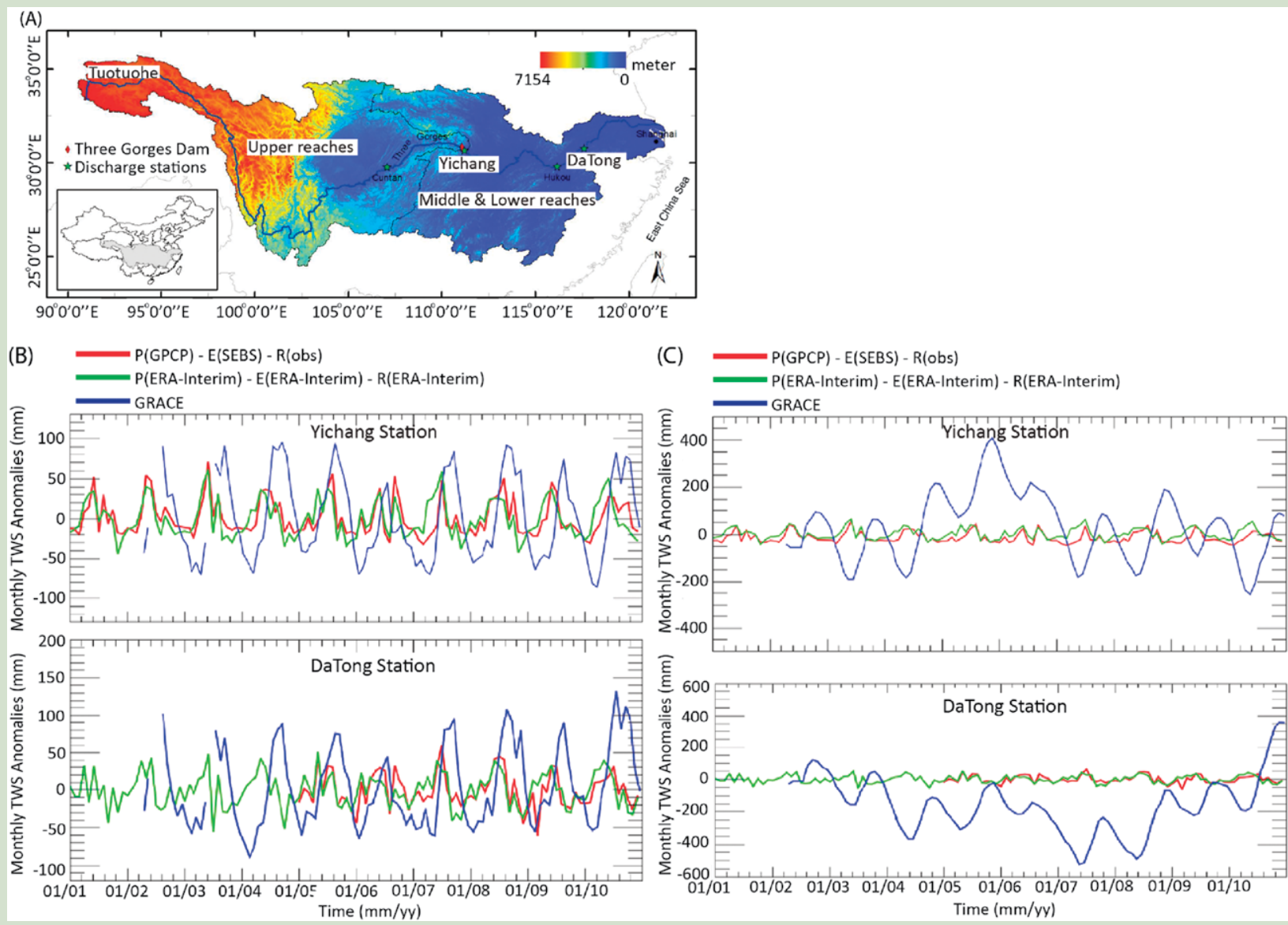

FIG. SBI. An application of the CORE-CLIMAX generic validation strategy (i.e., highlighting the importance of step 4-the consistency check) over the Yangtze River basin, using in situ measurements, satellite observations, and reanalysis data. This corresponds to the second type of (inter)comparison.

Currently, many CDRs are not yet suitable for use in reanalyses or in climate study applications. The production of consistent high-resolution data records remains a challenge and needs more research urgently. Linking ECVs to essential water variables is a next step for closing the gaps between CDRs and sectoral applications. Also the closing of other cycles (e.g., carbon and energy) requires more effort.

At the closure review meeting at the European Commission's Research Executive Agency held in Brussels, Belgium, on 22 June 2015, the external reviewer commented that CORE-CLIMAX has produced results far beyond its original scope. Ascertaining the maturity of climate data records involves many sensitive aspects and the best-practices approach of the CORE-CLIMAX project was met with community acceptance. Overall, CORE-CLIMAX has set a new paradigm for data handling and data quality regarding the development of climate services, and the authors hope this work can help direct and enhance these developments, to deliver sustainable climate services in which users can place confidence.

\section{ACKNOWLEDGMENTS. The CORE-CLIMAX} project was financially supported by the European Commission within the Copernicus initiative in its Seventh Framework Programme (FP7 Grant Agreement 313085). The CORE-CLIMAX consortium comprised seven European institutions: Faculty for Geo-Information Science and Earth Observation (ITC), University of Twente; EUMETSAT; ECMWF; German Weather Service (DWD); VITO; FMI; Météo-France; and two international institutions: the Institute of Tibetan Plateau Research (ITP) and the Cold and Arid Regions Environmental and Engineering 
Research Institute (CAREERI, now known as the Northwest Institute of Eco-Environment and Resources), both of the Chinese Academy of Sciences. We thank all project participants for their dedicated efforts in the project execution as well as the members of the CORE-CLIMAX Advisory Board for advice of high-level importance to the project. We are also thankful to participants of the CORECLIMAX workshops.

\section{APPENDIX: KEY ACRONYMS USED IN THIS PAPER.}

APM

BSRN

C3S

CCI

CDR

CDS

CEOS

CMUG

CORE-CLIMAX

ECA\&D

ECMWF

ECV

EQC

ERA-Interim

ESA

EUMETSAT

FCDR

GCOS

GEWEX

GPCC

GPCP

GRACE

HadObs

ISO

KNMI

NOAA

SAF

SMM

TCDR

TWS

USGS

WGC

WGCV

WMO
Application performance matrix

Baseline Surface Radiation Network

Copernicus Climate Change Service

Climate Change Initiative

Climate data record

Climate data store

Committee on Earth Observation Satellites

Climate Modeling Users Group

Coordinating Earth Observation Data Validation for Reanalysis for Climate Services

European Climate Assessment and Dataset

European Centre for Medium-Range Weather Forecasts

Essential climate variable

Evaluation and quality control

ECMWF interim reanalysis

European Space Agency

European Organisation for the Exploitation of Meteorological Satellites

Fundamental climate data record

Global Climate Observing System

Global Energy and Water Cycle Exchanges Project

Global Precipitation Climatology Centre

Global Precipitation Climatology Project

Gravity Recovery and Climate Experiment

Hadley Centre observational dataset

International Organization for Standardization

Koninklijk Nederlands Meteorologisch Instituut

National Oceanic and Atmospheric Administration

Satellite Application Facility

System maturity matrix

Thematic climate data record

Terrestrial water storage

U.S. Geological Survey

Working Group on Climate

Working Group for Calibration/Validation

World Meteorological Organization

\section{REFERENCES}

Adler, R. F., and Coauthors, 2003: The Version-2 Global Precipitation Climatology Project (GPCP) monthly precipitation analysis (1979-present). J. Hydrometeor., 4, 1147-1167, https://doi.org/10.1175/1525 -7541(2003)004<1147:TVGPCP >2.0.CO;2.

Bates, J. J., and J. L. Privette, 2012: A maturity model for assessing the completeness of climate data records. Eos, Trans. Amer. Geophys. Union, 93, 441, https:// doi.org/10.1029/2012EO440006.
Chen, X., Z. Su, Y. Ma, S. Liu, Q. Yu, and Z. Xu, 2014: Development of a 10-year (2001-2010) $0.1^{\circ}$ data set of land-surface energy balance for mainland China. Atmos. Chem. Phys., 14, 13 097-13 117, https://doi .org/10.5194/acp-14-13097-2014.

Dee, D. P., and Coauthors, 2011: The ERA-Interim reanalysis: Configuration and performance of the data assimilation system. Quart. J. Roy. Meteor. Soc., 137, 553-597, https://doi.org/10.1002/qj.828.

Dowell, M., and Coauthors, 2013: Strategy towards an architecture for climate monitoring from space. 
CEOS/WMO/CGMS Rep., 39 pp., www.wmo.int /pages/prog/sat/documents/ARCH_strategy-climate -architecture-space.pdf.

Gregow, H., and Coauthors, 2014a: Procedure for comparing reanalyses, and comparing reanalyses to assimilated observations and CDRs. European Union Seventh Framework Programme CORE-CLIMAX, 44 pp., www.coreclimax.eu/sites/coreclimax.itc .nl/files/documents/Deliverables/WP_Reports /Deliverable-D553-CORECLIMAX.pdf.

— , and Coauthors, 2014b: Reanalyses and user needs with respect to climate change services. European Union Seventh Framework Programme CORE-CLIMAX, 80 pp., www.coreclimax.eu/sites/coreclimax .itc.nl/files/documents/Deliverables/WP_Reports /Deliverable-D552-CORECLIMAX.pdf.

— , and Coauthors, 2016: Worldwide survey of awareness and needs concerning reanalyses and respondents views on climate services. Bull. Amer. Meteor. Soc., 97, 1461-1473, https://doi.org/10.1175 /BAMS-D-14-00271.1.

Huang, Y., M. S. Salama, M. S. Krol, Z. Su, A. Y. Hoekstra, Y. Zeng, and Y. Zhou, 2015: Estimation of human-induced changes in terrestrial water storage through integration of GRACE satellite detection and hydrological modeling: A case study of the Yangtze River basin. Water Resour. Res., 51, 8494-8516, https://doi.org/10.1002/2015WR016923.

John, V., and Coauthors, 2015: CORE-CLIMAX climate data record capacity assessment report. European Union Seventh Framework Programme CORE-CLIMAX, 253 pp., www.eumetsat.int/website/wcm/idc /idcplg? IdcService $=$ GET_FILE\&dDocName $=$ PDF _CORE_CLIMAX_CAP_ASSESS\&RevisionSelection Method=LatestReleased\&Rendition=Web.

Kaiser-Weiss, A. K., F. Kaspar, V. Heene, M. Borsche, D. G. H. Tan, P. Poli, A. Obregon, and H. Gregow, 2015: Comparison of regional and global reanalysis near-surface winds with station observations over Germany. Adv. Sci. Res., 12, 187-198, https://doi .org/10.5194/asr-12-187-2015.

Landerer, F. W., and S. C. Swenson, 2012: Accuracy of scaled GRACE terrestrial water storage estimates. Water Resour. Res., 48, W04531, https://doi .org/10.1029/2011WR011453.

Poli, P., D. Tan, V. John, and J. Schulz, 2013: Procedure for feeding back improved ancillary data to assist climate data records updates. European Union
Seventh Framework Programme CORE-CLIMAX, 14 pp., www.coreclimax.eu/sites/coreclimax.itc .nl/files/documents/Deliverables/WP_Reports /Deliverable-D441-CORECLIMAX.pdf.

Schulz, J., 2015: CORE-CLIMAX structured process for the generation of climate data records. European Union Seventh Framework Programme CORECLIMAX, 24 pp., www.coreclimax.eu/Deliverables /Deliverable-D226-CORECLIMAX.pdf.

Stubenrauch, C. J., and Coauthors, 2013: Assessment of global cloud datasets from satellites: Project and database initiated by the GEWEX Radiation Panel. Bull. Amer. Meteor. Soc., 94, 1031-1049, https://doi .org/10.1175/BAMS-D-12-00117.1.

Tan, T., and P. Poli, 2013: Design of support infrastructure for CDR quality assessment in a reanalysis environment. European Union Seventh Framework Programme CORE-CLIMAX, 27 pp., www.core climax.eu/sites/coreclimax.itc.nl/files/documents /Deliverables/WP_Reports/Deliverable-D442 -CORECLIMAX.pdf.

- - —, and J. Schulz, 2014: Procedures for feeding back reanalysis results and plans to CDR producers. European Union Seventh Framework Programme CORE-CLIMAX, 16 pp., www.coreclimax.eu/sites /coreclimax.itc.nl/files/documents/Deliverables /WP_Reports/Deliverable-D443-CORECLIMAX.pdf.

Zeng, Y., and Coauthors, 2014a: Assessment report on consistency validation of the CDRs/ECVs. European Union Seventh Framework Programme CORECLIMAX, 55 pp., www.coreclimax.eu/Deliverables /Deliverable-D332-CORECLIMAX.pdf.

— , and Coauthors, 2014b: Generic validation strategy for ECV CDRs. European Union Seventh Framework Programme CORE-CLIMAX, 24 pp., www .coreclimax.eu/Deliverables/Deliverable-D333 -CORECLIMAX.pdf.

— , and Coauthors, 2015: Analysis of current validation practices in Europe for space-based climate data records of essential climate variables. Int. J. Appl. Earth Obs. Geoinf., 42, 150-161, https://doi .org/10.1016/j.jag.2015.06.006.

— , Z. Su, R. Van der Velde, L. Wang, K. Xu, X. Wang, and J. Wen, 2016: Blending satellite observed, model simulated, and in situ measured soil moisture over Tibetan Plateau. Remote Sens., 8, 268, https://doi .org/10.3390/rs8030268. 


\section{Find out from the authoritative source}

[ What's a dust devil? ]

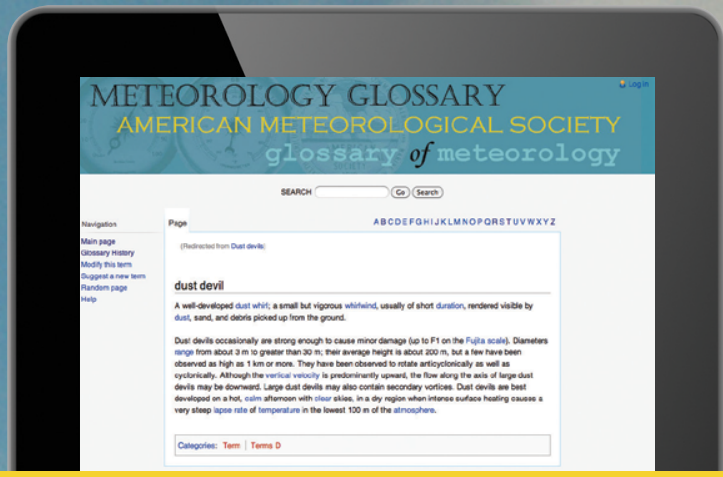

THE AMERICAN METEOROLOOICAL SOCIETV

\section{Online Glossary of Meteorology}

With over 12,000 meteorological terms, you'll be able to look up definitions online any time, any place, anywhere. http://glossary.ametsoc.org/wiki 